\title{
Red State/Blue State Divisions in the 2012 Presidential Election
}

\begin{abstract}
The so-called "red/blue paradox" is that rich individuals are more likely to vote Republican but rich states are more likely to support the Democrats. Previous research argued that this seeming paradox could be explained by comparing rich and poor voters within each state - the difference in the Republican vote share between rich and poor voters was much larger in low-income, conservative, middle-American states like Mississippi than in high-income, liberal, coastal states like Connecticut. We use exit poll and other survey data to assess whether this was still the case for the 2012 Presidential election. Based on this preliminary analysis, we find that, while the red/ blue paradox is still strong, the explanation offered by Gelman etal. no longer appears to hold. We explore several empirical patterns from this election and suggest possible avenues for resolving the questions posed by the new data.
\end{abstract}

*Corresponding author: Avi Feller, Department of Statistics, Harvard University, 1 Oxford Street, Cambridge, MA 02138, USA, E-mail: avifeller@fas.harvard.edu

Andrew Gelman: Department of Statistics, Columbia University, Amsterdam Ave. at 122 St., New York, NY 10027, USA

Boris Shor: University of Chicago and University of California, Berkeley

\section{Introduction}

Since the Bush-Gore election, political observers in the US have been confused by what we call the "red/blue paradox." Some recognize that Democratic presidential candidates consistently win the richer states and Republicans win the poorer states. Others notice that at the individual level, richer people vote 10 to 20 percentage points more Republican than poorer ones. These patterns are not new: the correlation between state income and Democratic voting picked up in the 1980s and 1990s and has remained strong in the George W. Bush and Obama elections. Even more, the correlation between individual income and Republican voting has held, with only brief interruptions, at least since the 1940s.

In unifying and reconciling these individual and statelevel patterns, Gelman and his coauthors $(2008,2009)$ found that the income-voting gradient - the difference in the Republican vote share, comparing upper-income to lower-income voters - was much larger in poor states than in rich states. The income divisions between the two parties were largest in low-income, conservative, middle-American states such as Mississippi, and smallest in high-income, liberal, coastal states such as New York and California.

This latter pattern has several implications. First, the national media happen to be located in states with a low correlation between income and how people vote. Thus, it is understandable that many national reporters and political pundits tended to think of the election in postmaterialist terms, as a battle of social frames rather than of economic policies. Had these reporters been based in Texas or Oklahoma, say, rather than Maryland and Virginia, they might have been more aware of the large and persistent economic differences between the supporters of the two parties.

A second implication of the red state/blue state pattern is that the differences between "red America" and "blue America" have been largest among uppermiddle-class and rich voters, and much less so among lower-income voters. That is, the culture war in American politics has been largely happening in the upper half of the income distribution. At least, that was the case up through 2008. Having analyzed poll data from previous elections in depth to understand this interplay between geography, demographics, and voting, we wondered to what extent these patterns persisted in 2012.

\section{What Happened in 2012}

We studied earlier elections using pre-election polls from the National Election Study (since 1948), the Annenberg Election Survey (for 2000-2008), and Pew Research surveys (for 2008). We also checked our results using exit polls, but the pre-election surveys (after demographic adjustments for sampling and non-response, and stateby-state adjustments to the actual election outcome) are generally considered to be more reliable. For 2012, we do not yet have the large name-brand political surveys but we took our first shot using two available data sources: state-by-state exit poll summaries as published on many 
national news websites, and a national survey conducted by one of us with funding from the Robert Wood Johnson (RWJ) Foundation. The results from these surveys are what we report here.

\section{Some Findings Consistent with Previous Research}

First, based on these preliminary data, we find that the overall red/blue paradox still holds for the 2012 election: based on exit polls, around 54\% of individuals with annual incomes above $\$ 100,000$ voted for Romney compared to just $35 \%$ among those making $<\$ 30,000$. At the same time, Romney won $61 \%$ of the two-party vote in the poorest five states compared to just 39\% in the richest five states:
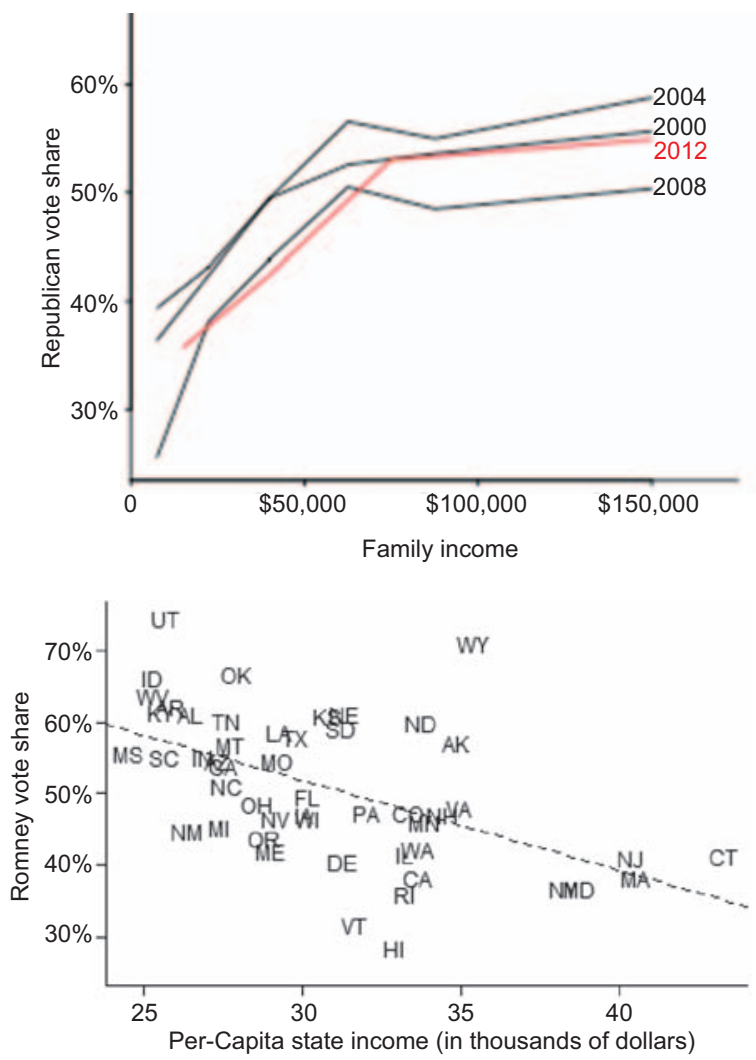

Second, partisan divisions remain concentrated among wealthier individuals. To see this, compare the five states in the thirty states in the exit poll universe ${ }^{1}$ that had the highest support for Romney (Indiana, Mississippi, Montana, Kansas, and Alabama) with the five states that had the lowest support for Romney (Vermont, New York,

1 As a cost saving measure, the media exit poll conglomerate only polled the 30 most competitive states.
Maryland, California, and Massachusetts). Among voters earning $<\$ 30,000$ per year, the percent supporting Romney is $25 \%$ (of the two-party vote) in the Democrat states and $44 \%$ in the Republican states - all in all, a nationwide loss for Romney among this demographic. In contrast, among voters earning between $\$ 100,000$ and $\$ 200,000$ per year, Romney support varies from $45 \%$ in the Democratic states to a strong $69 \%$ in the Republican states:

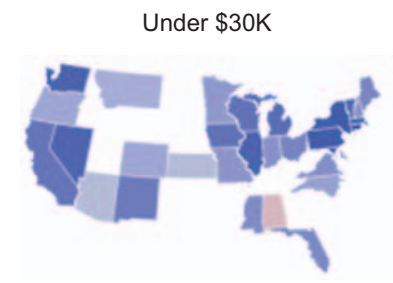

$\$ 50-100 K$

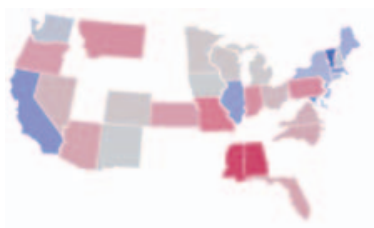

$\$ 30-50 K$
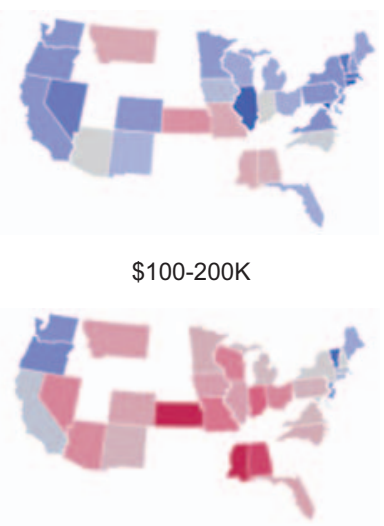

We observe a similar pattern among other demographic groups, especially by race. Among White voters, $70 \%$ support Romney in the five most Republican states compared to $47 \%$ in the five most Democratic states. Among non-White voters, however, the picture is striking a paltry $15 \%$ support Romney in the most Republican states, compared to $10 \%$ in the most Democratic states. Comparing men and women we see similar patterns but to a lesser extent, which makes sense, given that the gender gap is smaller than ethnic and racial gaps in vote preference: ${ }^{2}$
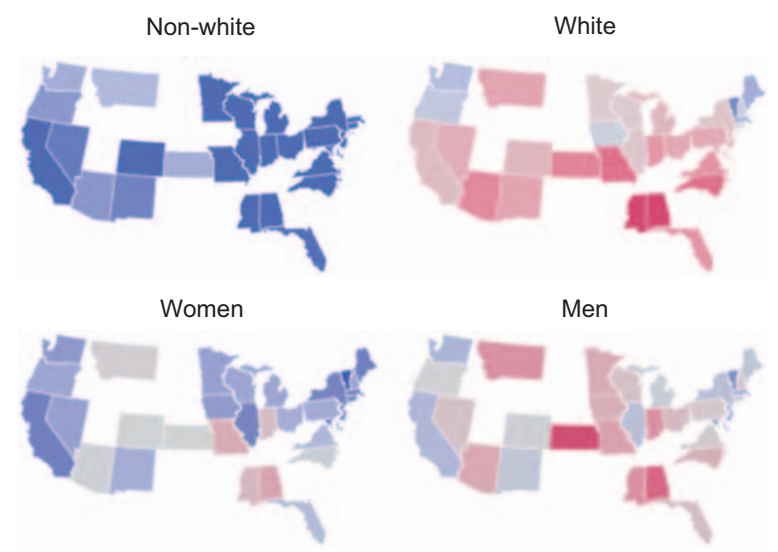

2 In the top five most Republican states, $61 \%$ of men support Romney compared to just $42 \%$ in the five most Democratic states. For women, these numbers are uniformly lower - 52\% Romney support in the most Republican states and 32\% in the most Democratic states. 
Finally, we observe a strong pattern by age, similar to the 2008 election (but not 2000 or 2004), with much more divergence among older voters than among, say, 18 to 29 year olds.

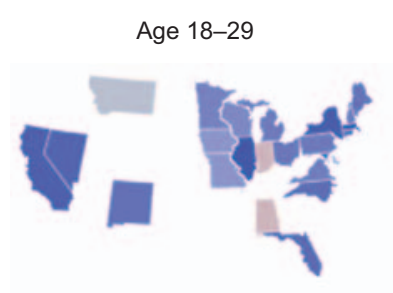

Age 40-64
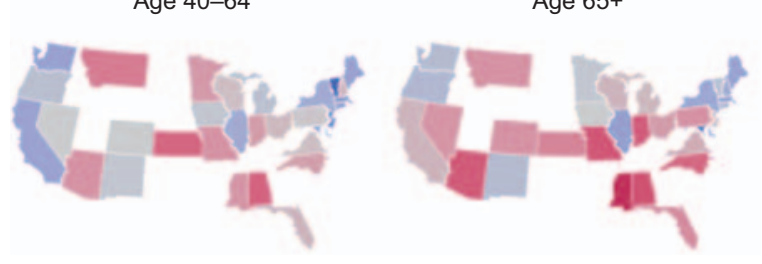

\section{New Questions From 2012}

Our previous Red State, Blue State research found a strong negative relationship between overall state income and the income-voting gradient. In other words, in Mississippi (the poorest state) rich voters were much more likely to vote Republican than poor voters; in Connecticut (the richest state) rich voters were only slightly more - or sometimes not at all more - likely to vote Republican than poor voters. These patterns have held consistently since 1992. But, to our surprise, based on preliminary evidence, they do not appear to hold for the 2012 election.

We begin with the richest and poorest states. In Mississippi, $37 \%$ of voters with family income $<\$ 30,000$ per year supported Romney, compared to $75 \%$ among those earning between $\$ 100,000$ and $\$ 200,000$ - a swing of $38 \%$. For Connecticut, this low-high income swing is $27 \%$. We can improve these estimates by fitting simple weighted

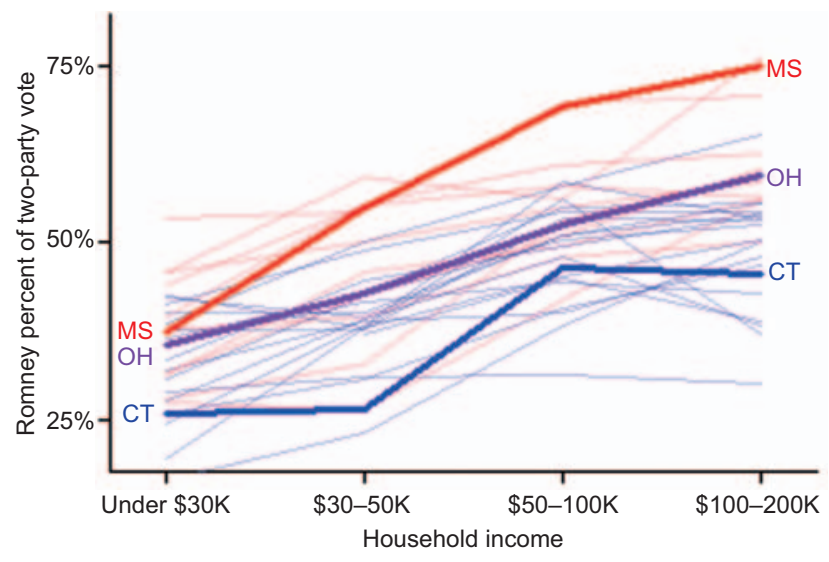

regression lines across the income categories, yielding a slope of 0.51 for Mississippi and 0.22 for Connecticut. These results can be roughly interpreted as the difference between how rich and poor vote within each state, comparing individuals 1 standard deviation above and 1 standard deviation below the average. ${ }^{3}$ So far, this is consistent with the results from Red State, Blue State.

However, Mississippi appears to be an outlier among the exit polls. The rich-poor difference is 19 percentage points in the five poorest states compared to 26 percentage points in the five richest states - a discrepancy that is small compared to the variation between states. This can also be seen by comparing the vote-income slopes: an average of 0.24 for the richest five states and 0.23 for the poorest five states. In general, there is no compelling evidence from the exit poll data suggesting that the voteincome slope is smaller in rich states than in poor states.

To confirm this, we examined data from an election-eve survey of 5000 registered voters written by Boris Shor and Ryan T. Moore, sponsored by the Robert Wood Johnson Foundation. Since we had access to the individual-level data, we were able to use multilevel modeling to partially pool estimates across states, improving the stability of the results, especially for the smaller states. If anything, however, the survey results suggest that the vote-income slope is greater in richer states, quite the opposite of what we have seen in other national elections of the past two decades.

What do we see from these graphs? First, all the points are above zero; that is, higher-income people vote more Republican than lower-income people in every state. Second, any relation between state income and vote-income slope is weak, in contrast to patterns we have seen in previous elections - especially for the exit polls. Third, there is much more variation in the state slopes as estimated in the exit poll compared to those from the Shor-Moore survey. This last difference can be explained by methodology: we estimated the slopes from exit polls using summary data from each state, whereas with the survey we had raw data and could fit a multilevel model which gives more stable estimates, yielding a more precise estimate for each state but probably understating the variation between states. Using either method, the message is clear: based on these polls, the pattern described in Red State, Blue State did not hold in 2012.

3 We treat income categories as numeric and rescale them by subtracting the mean and dividing by two times the standard deviation, as recommended in Gelman (2008). We perform a separate normalization for the exit polls and RWJ polls, for each of these we use a single consistent normalization for the whole country. 
Exit poll results: Unpooled regression estimates
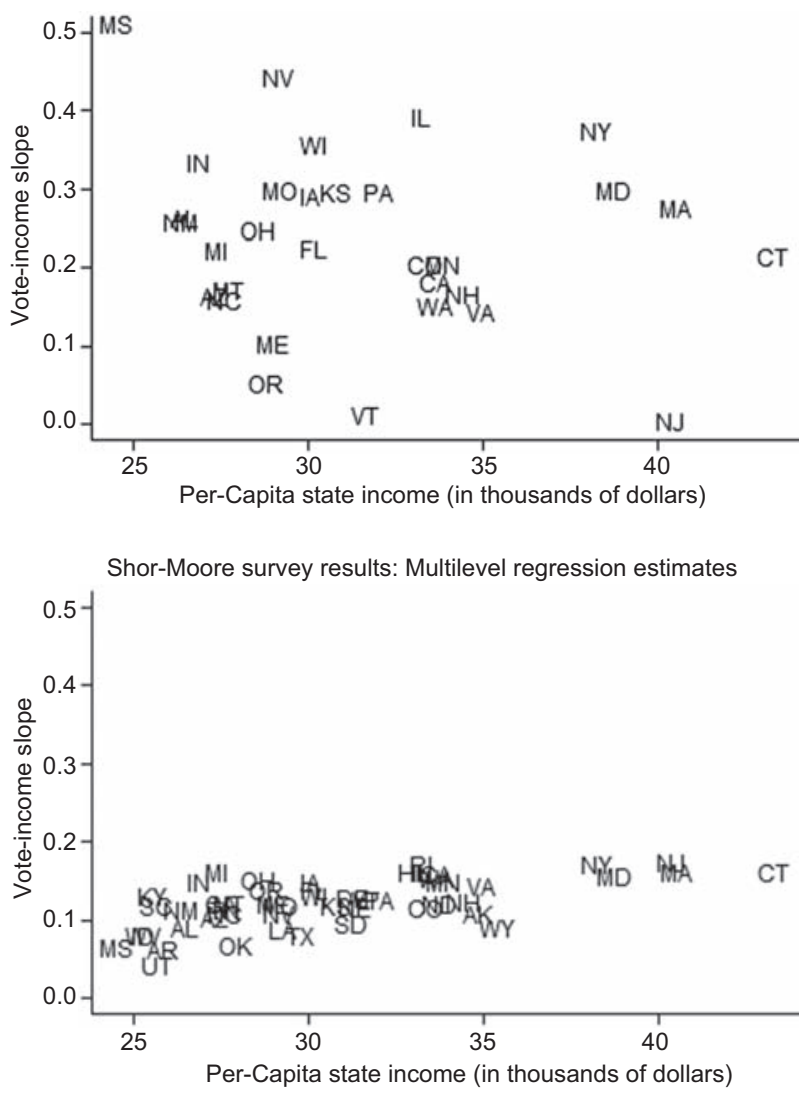

\section{Discussion}

The first major point of Red State, Blue State was the existence of the red/blue paradox: rich states support Democrats, but rich individuals tend to vote Republican. Based on preliminary data, this pattern persisted into 2012, with poorer voters continuing to vote strongly for Democrats nationwide and richer ones weakly leaning Republican, but with richer states much more likely to vote Democratic. This pattern also holds within each state - richer voters were more Republican and poorer voters were more Democratic.

The second major story of Red State, Blue State was that, especially in rich, coastal areas, wealthier voters are conflicted between their economic conservatism and cultural liberalism, contributing to flatter slopes for Republican vote share by income. In other areas, especially in poorer, heartland areas, economic and cultural conservatism reinforce each other among wealthier voters, leading to a much steeper vote-income slope. Based on the available data, however, this pattern - which began in 1992 and remained strong throughout the elections of the 2000s seems to have stopped in 2012.

While stronger conclusions must wait until more detailed data, these findings do suggest several points and raise several questions:

- First, the persistence of the red/blue paradox through 2012 means that many common political themes will likely continue as well. Specifically, we continue to regard the Republican Party as a coalition between the middle class and the rich, and the Democrats as a coalition between the poor, middle class, and rich. And given that upper-income voters are roughly split between the two parties - and are of course overrepresented among campaign contributors much of the differences between the two parties can be identified as differences between rich liberals and rich conservatives.

- Second, given Romney's extremely weak performance among non-Whites, race clearly plays a key role in these patterns. However, even among Whites alone, we can deduce a positive correlation between income and Republican voting, consistent with previous elections. ${ }^{4}$ Age was also a strong predictor of voting Republican in the 2012 election. This latter pattern is a relatively recent development, starting in 2006, and continues to have implications for healthcare and retirement policy [see also Gelman, Lee, and Ghitza (2010)]. For both of these key demographic factors, however, we will need much more detailed data to parse this out fully.

Considering the persistence of these overall trends, the absence of different vote-income gradients between rich and poor states is especially puzzling. We cannot yet explain this change in 2012. However, this puzzle does suggest that we should probably re-evaluate how we think about the relationship between voting and income in the US, following work such as that of McCarty, Poole, and Rosenthal (2006) and Bartels (2008), which connect trends in partisanship, economic inequality, and voting patterns among different economic strata.

4 As discussed in Gelman etal. (2009), it is possible to estimate White voting patterns in much of the country, even in the absence of individual-level poll data, by subtracting out non-Whites votes. This is because voting patterns vary much less among non-Whites than among whites and publicly available survey data give us state-bystate estimates of voting patterns by race. 


\section{References}

Bartels, Larry M. 2008. Unequal Democracy: The Political Economy of the New Gilded Age. Princeton University Press.

Gelman, Andrew. 2008. "Scaling Regression Inputs by Dividing by Two Standard Deviations." Statistics in Medicine 27: 2865-2873.

Gelman, Andrew and Avi Feller. 2012. "Red Versus Blue in a New Light.” New York Times, November 12, 2012. http:// campaignstops.blogs.nytimes.com/2012/11/12/red-versusblue-in-a-new-light/

Avi Feller is a PhD Student in the Department of Statistics, Harvard University; e-mail: avifeller@fas.harvard.edu.

Andrew Gelman is a Professor in the Department of Statistics and Political Science, Columbia University.

Boris Shor is a Robert Wood Johnson Foundation Scholar in Health Policy and Assistant Professor in the Harris School of Public Policy at the University of Chicago and University of California, Berkeley.
Gelman, Andrew, Daniel Lee, and Yair Ghitza. 2010. "Public opinion on health care reform." The Forum 8(1): 1-14.

Gelman, Andrew, David K. Park, Boris Shor and, Jeronimo Cortina. 2009. Red State, Blue State, Rich State, Poor State: Why Americans Vote the Way They Do (Expanded Edition). Princeton University Press.

McCarty, Nolan, Keith T. Poole, and Howard Rosenthal. 2006. Polarized America: The Dance of Ideology and Unequal Riches. MIT Press. 